\title{
The Technical Difficulties of Directional Well and Horizontal Well Logging in Bohai Oilfield
}

\author{
Jiaxu Li \\ Tianjin Branch of CNOOC (China) Co., Ltd., Tianjin Tanggu 300459
}

\begin{abstract}
Due to the limitation of offshore oil drilling platform, cluster well drilling technology is generally used now, directional well and horizontal well are widely used, and the technology is more and more mature. In the process of directional well and horizontal well drilling, logging work is greatly affected. How to grasp the formation conditions and correctly divide the oil, gas and water layers has become a difficult problem for many geologists, which requires us to study and analyze the impact of logging work in the process of directional well and horizontal well operation, so as to solve a series of problems encountered in the field.
\end{abstract}

Keywords: Directional well, Horizontal well, Mud logging technology, Influence, Countermeasure.

\section{The Definition of Directional Well and Horizontal Well}

Directional well is a well whose design target point deviates a certain distance from the wellhead vertical line in a given direction. Highly deviated directional well means that the maximum deviation angle exceeds $60^{\circ}$ It's a good well. Extended reach well is a directional well whose ratio of horizontal displacement to vertical depth is greater than or equal to 2. A horizontal well is a well with an angle of $90^{\circ}$ And a certain length of well is drilled along the horizontal direction.

\section{The Influence of Directional Well and Horizontal Well Operation on Mud Logging and Countermeasures}

From conventional directional wells to highly deviated wells and even horizontal wells, with the increase of well deviation angle, the gravity changes from favorable factors to unfavorable factors, such as the increase of friction, which leads to the difficulties of tripping, applying WOB and putting instruments into the well; The tendency of solid phase precipitation in drilling fluid and cement slurry increases, which increases the possibility of sticking and other downhole accidents. This determines that highly deviated wells and horizontal wells are obviously different from conventional directional drilling in wellbore design, wellbore trajectory control, drilling fluid and other technical aspects.

Compared with the vertical well, the directional well drilling construction has greater risk, such as the increase of factors causing drilling accidents, there is also the risk that it is difficult to achieve the geological purpose. Affected by the inherent characteristics of directional well and new drilling technology, geological logging for this kind of well will encounter much more complex difficulties than conventional logging, mainly in the following aspects.

\subsection{Impact on Engineering Parameters}

Drilling time can not accurately reflect formation lithology and physical properties. In normal vertical well drilling, when drilling parameters are relatively stable, the variation of drilling time is mainly related to lithology, and drilling time data is an important reference for qualitative judgment of lithology and lithologic stratification in cuttings description. However, in the process of directional drilling, the drilling tools are easy to stick to the wellbore, and the contact area between centralizer and drill collar and the wellbore is large. In horizontal drilling, some drilling tools will lie flat on the wellbore, which reduces the WOB transmitted to the bit and increases the drilling time; At the same time, in order to meet the needs of directional construction such as deviation making, deviation increasing and deviation decreasing, it is often necessary to adjust the engineering parameters such as WOB, rotary table speed and displacement, so it is difficult to truly reflect the drillability of formation during drilling.

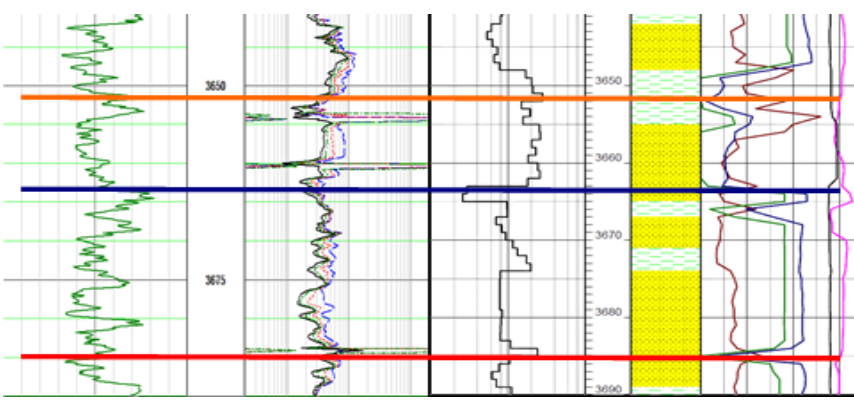

Figure 1: Comparison of logging map and comprehensive logging map

The complexity of downhole situation makes it more difficult to detect the engineering parameters and predict the anomalies. Especially with the continuous change of drilling methods, it is difficult to make timely and accurate prediction of underground anomalies when the variation characteristics of engineering parameters under various drilling methods are not clear. This requires comprehensive logging personnel to make timely prediction of Engineering anomalies with high sense of responsibility, keen intuition and accurate judgment, so as to ensure the safety of drilling construction.

\subsection{The Impact on Cuttings Logging}

In the process of directional well and horizontal well drilling, cuttings return is not only closely related to drilling fluid displacement, performance, revolutions, cuttings size, density 
and geometric shape, but also controlled by well inclination and cuttings operation mode, so it is difficult to judge the late time in the process of directional drilling.

Due to the need of PDC bit to improve drilling efficiency, special drilling tool structure and complicated borehole conditions, cuttings logging can not be carried out step by step according to the operation method of vertical well. The main performance is as follows: the complexity of drilling tool structure and well depth structure leads to the change of cuttings migration mode, and the cuttings formed are fine and mixed with poor representativeness; It is difficult to accurately determine the lateness of cuttings; The cuttings are repeatedly ground in the well, so that the fine cuttings are suspended in the annulus in the form of powder. The cuttings in the mud logging are small, and even the real cuttings can not be retrieved. Especially in the areas with poor diagenesis of Cenozoic and easy hydration of mudstone, the cuttings retrieved during drilling are basically sandstone, and it is difficult to see mudstone, and the formation drillability is good, so it is difficult to distinguish lithology through drilling.

\subsection{The Impact on Gas Logging and Countermeasures}

As the most direct and effective method to judge oil and gas reservoir, gas logging plays a very important role in the process of field logging. When the drilling fluid is not mixed with crude oil, with the drilling of oil and gas reservoir, the measured value of gas changes obviously, and the total hydrocarbon and components increase correspondingly. In the construction of horizontal wells, in order to ensure the safety of downhole drilling, crude oil is often mixed into the drilling fluid to improve the lubricity of the drilling fluid, but it has a great impact on gas logging.

Gas logging and cuttings logging complement each other to carry out comprehensive interpretation of oil and gas shows. By analyzing the different characteristics of true and false gas logging, the reservoir can be accurately evaluated. The oil-based drilling fluid used in directional well drilling makes the total hydrocarbon base value of gas logging increase, but the base value is relatively stable, generally only a small amount of methane and heavy components, which can be used as the overall gas logging base value before entering the target formation. When organic additives which affect gas logging are added into drilling fluid, the light components such as methane in the components will decrease until they disappear. In drilling, once the light components such as methane and ethane appear or increase, it can be judged that they enter the oil and gas reservoir. When the non hydrocarbon parameters change, it can be judged whether drilling in the same reservoir by referring to the change of non hydrocarbon parameters. It is very important to reduce the error caused by gas detection system and ensure the accuracy of gas detection system. In the process of comprehensive analysis, gas logging anomaly needs to be confirmed by lithology and cuttings fluorescence test. At the same time, cuttings fluorescence test is more targeted because of gas logging anomaly. Both of them verify each other. Comprehensive analysis can accurately implement oil and gas display.

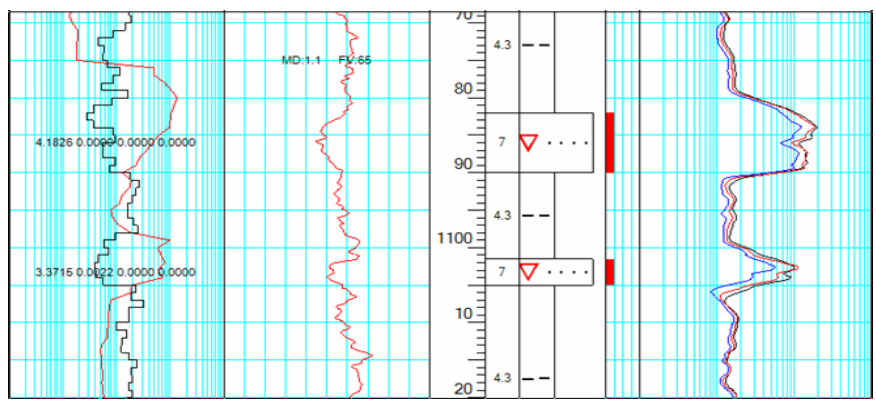

Figure 2: Gas advance in horizontal well logging

In the process of directional well and horizontal well construction, the change of formation and engineering parameters will lead to the corresponding change of gas logging value, so attention should be paid to the identification.

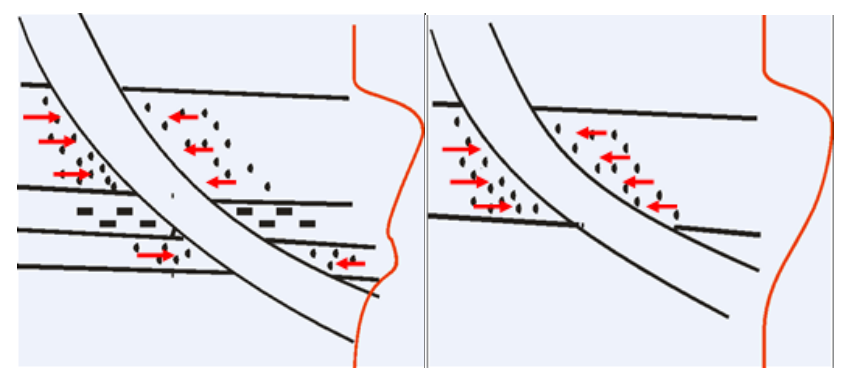

Figure 3: Effect of well trajectory on gas logging

\subsection{The Impact on Fluorescence Logging and Countermeasures}

In the process of directional well and horizontal well logging, it is more difficult to implement and return oil and gas display. The fluorescence display of cuttings is weak, especially for some light oil reservoirs with new formation age and poor diagenesis. After a long time of scouring and soaking in the borehole, the oil and gas loss is serious, so it is difficult to find and implement the oil and gas display with conventional fluorescence logging method. In order to deal with the complex downhole situation and reduce the friction of drilling tools, organic additives and mixed oil drilling fluid are often used in directional well drilling, which will greatly interfere with fluorescence logging and gas logging.

\section{Conclusion}

In practical work, due to the complexity of directional well and horizontal well, various logging technologies need to be fully combined and complemented with each other, various factors need to be comprehensively analyzed, and the emphasis should be timely adjusted according to the on-site logging situation. In a word, only by mastering the advanced logging technology, knowing well the field data and regional geological data, and comprehensively analyzing and judging various situations, can the successful drilling of directional wells and horizontal wells be realized.

\section{References}

[1] Yang Liping, Yang Jin. Foundation and Application of Modern Comprehensive logging Technology [M]. Petroleum Industry Press, 2008. 
[2] Liang Bo, Jiang Yongfu. Technical methods of large displacement inclined and horizontal well logging [J]. Western Exploration Project, 2004, 2016(11): 55-57.

[3] Zhang Lei Lei, Li Yongsheng, Zhang Yanqi, Wang Zhou Su. Theoretical Application Analysis of Horizontal logging Technology [J]. Inner Mongolia Petrochemical Industry, 2009, 35(10): 151-152.

[4] Wang Huiyun. Analysis on Technical Difficulties of Directed logging [J]. Scientific and Technological Intelligence Development and Economy, 2009, 19(10): 199-201.

[5] Poplar, Zhang Jingfu, Shen Nian. Experimental study on drilling fluid in large slope well [J]. Journal of Daqing Petroleum Institute, 1997(01): 128-131. 